\title{
OSI Scholarly Societies and Society Publishers Stakeholders
}

\section{Report}

Kris Bishop, Karla Cosgriff, Michael Forster, Diane Scott-Lichter, Brian Selzer, Crispin Taylor, Emma Wilson

\section{Charge and Members}

The 2017 Scholarly Societies and Society Publishers Stakeholder group discussed the various approaches to publishing that was represented around the table. Representatives in this group came from science disciplines and represented all sizes of organizations and publishing arrangements (i.e. small and large independent publishers, and those that partner with for-profit publishers under various arrangements).

\section{Assumptions \& Challenges}

To guide their conversations, the stakeholder group agreed to a set of baseline assumptions, the most important of which is that to ensure and maintain high quality publishing operations, the society must have a sustainable business model. For all of the groups represented, journal publications and ancillary activities are not only self-sustaining but also fund many other society programs such as awards and education programs. This position is similar to the situation that keynote speaker Vint Cerf described at the Association for Computing Machinery (ACM), where he previously served as president. At ACM, thirty percent of funding for programs came from publishing surpluses. The group questioned whether it is possible to replace the subscription revenue with other forms C 2017 OSI2017 Scholarly Societies and Society Publishers Stakeholder workgroup. This open access article is distributed under the Creative Commons Attribution 4.0 International License. This document reflects the combined input of the authors listed here (in alphabetical order by last name) as well as contributions from other OSI2017 delegates. The findings and recommendations expressed herein do not necessarily reflect the opinions of the individual authors listed here, nor their agencies, trustees, officers, or staff. of support, including philanthropic, to keep these programs going.

One of the groups represented, The Electrochemical Society (ECS), which is relatively small compared to the others in the stakeholder group, is trying to go to a platinum open access model (Free the Science) by raising philanthropic support for this change in business model. The stakeholder group acknowledged that this kind of model cannot work for everyone because in some cases the publishing operations are just too large.

Similarly, the group concluded that there is not one right model for the future of open access. There probably needs to be a mixed economy of business and funding models. One of the ways that costs to publish could be reduced would be for smaller or independent society publishers to realize economies of scale and share platform expenses. There may also be opportunities to use open-sourced software that is being developed.

There is, however, a perceived concern that a gold open access, APC-based economy may result in competition on price and a lowest common denominator level of service/quality.

The bottom line is that the missions of the scholarly societies represented encompass 
a responsibility to steward and advance research but that does not always fit well with publishing-centric revenue models. A shift away from traditional publishing operations is, therefore, a delicate budgetary and public relations issue for which no one yet has the answer.

\section{Future Roles for Society}

\section{Publishers}

The group discussed way in which societies could play a bigger role in the shift toward greater openness and sharing. The most important role is educating their constituencies on the benefits and requirements of open access that can help perpetuate a culture change. Beyond that, they could offer platforms and recognition for those making the shift:

- Managing member metadata

- Connecting, tracking, and rewarding contributions

- Discipline-specific awards for "open"

- Scholarly Communication Networks

- Micro-credentialing

One example of the beginnings of some of the aforementioned comes from one of the stakeholders, the American Society of Plant Biologists: https://plantae.org/.

\section{Next Steps}

Scholarly societies and society publishers are in a unique position to influence the move toward open because they represent large groups of professional constituencies. To better understand the landscape, the stakeholder group recommends the following action steps:

1. Socialize concepts of open access to a greater extent within communities.

2. Bring together independent society publishers to determine if collaborations can be made. Determine how to increase efficiencies across the ecosystem.

3. Determine how the funds in the system can be redistributed (institutionally, nationally, internationally) to provide a more transparent economic relationship among producers, consumers, and publishers of information.

For any of these collaborations or developing economies of scale, societies must trust each other and have shared values.

\section{Scholarly Societies and Society Publishers Stakeholder Group:}

Kris Bishop, Product Manager, American Association for the Advancement of Science (AAAS)/Science Family of Journals

Karla Cosgriff, Director of Advancement, Free the Science, The Electrochemical Society

Michael Forster, Managing Director, IEEE Publications

Diane Scott-Lichter, Sr. Vice President, Publishing, American College of Physicians; Chair, AAP/PSP Executive Committee

Brian Selzer, Assistant Director of Publications, American Public Health Association

Crispin Taylor, CEO, American Society of Plant Biologists

Emma Wilson, Director of Publishing, Royal Society of Chemistry 